\title{
Direct Medical Costs of Incident Complications in Patients Newly Diagnosed With Type 2 Diabetes in China
}

\author{
Xiaoning He $\cdot$ Yawen Zhang $\cdot$ Yan Zhou $\cdot$ Chaohui Dong \\ Jing Wu (B)
}

Received: September 26, 2020 / Accepted: November 4, 2020 / Published online: November 18, 2020

(c) The Author(s) 2020

\begin{abstract}
Introduction: Reliable country-specific incidence and cost data on diabetes-related complications are essential inputs for the projections of the economic burden of diabetes. The aim of this study was to provide patientlevel cost estimates of managing and treating complications in patients newly diagnosed with type 2 diabetes mellitus (T2DM) in China.

Methods: Patients newly diagnosed with T2DM in the Tianjin Urban Employee Basic Medical Insurance Claims database between 2008 and 2015 were identified and followed up. The cumulative incidence and descriptive costs of certain macrovascular and microvascular complications were examined. A generalized
\end{abstract}

Electronic supplementary material The online version of this article (https://doi.org/10.1007/s13300020-00967-y) contains supplementary material, which is available to authorized users.

X. He · Y. Zhang · Y. Zhou · C. Dong · J. Wu ( $ه)$ School of Pharmaceutical Science and Technology, Tianjin University, Tianjin 300072, China e-mail: jingwu@tju.edu.cn

X. He $\cdot$ Y. Zhang $\cdot$ J. Wu

Center for Social Science Survey and Data, Tianjin University, Tianjin, China

Y. Zhou $(\bowtie)$

College of Management and Economics, Tianjin

University, Tianjin, China

e-mail: zhouyantj@tju.edu.cn estimating equations model was used to estimate the immediate- and long-term costs for the incident complication in quarterly intervals, controlling for demographics and the confounding effects of comorbid complications.

Results: A total of 114,847 newly diagnosed patients were identified (mean age 56.9 years, $45.5 \%$ women). After 7 years, $80.8 \%$ of the patients at risk had developed nephropathy and $75.7 \%$ had developed neuropathy. The immediate additional costs were highest for myocardial infarction during the quarterly interval that the complication first occurred (China yuan [CNY] 19,633), and the long-term costs were highest for stroke in the quarterly intervals of subsequent years (CNY 1087). The expected costs for all complications were calculated and presented as costs per quarterly interval and per year for different age and sex subgroups.

Conclusions: Managing complications results in substantial costs to the Chinese healthcare system. Our study contributes towards quantifying the economic burden and supports the parametrization of economic models of diabetes in China.

Keywords: Diabetes complications; Diabetes mellitus; Health care costs; Incidence; Type 2 


\section{Key Summary Points}

\section{Why carry out this study?}

The aim of this study was to provide patient-level cost estimates of managing and treating complications in patients newly diagnosed with type 2 diabetes mellitus in China.

Reliable country-specific cost data of diabetes-related complications are essential inputs for the projections of economic burden and economic evaluation models.

\section{What was learned from the study?}

Estimates of the cumulative incidence and individual-level costs of all chronic complications were determined.

Immediate additional costs were highest for myocardial infarction and stroke, and the long-term costs were highest for stroke and peripheral vascular disease.

This comprehensive set of incidence and cost data of diabetes-related complications will facilitate projections of the economic burden and economic evaluations for diabetes-related health interventions in China.

\section{DIGITAL FEATURES}

This article is published with digital features, including a summary slide, to facilitate understanding of the article. To view digital features for this article go to: https://doi.org/10.6084/ m9.figshare.13186808.

\section{INTRODUCTION}

Diabetes is a serious threat to global health, currently affecting more than 463 million people worldwide, of whom 116.4 million live in
China [1]. Type 2 diabetes mellitus (T2DM) accounts for more than $90 \%$ of all diabetes cases. Uncontrolled diabetes leads to a number of macrovascular (cardiovascular and cerebrovascular) and microvascular (nephropathy, diabetic foot, and retinopathy) complications, which contribute still further to a reduced quality of life, premature mortality, increased need for health care, and considerable healthcare expenditures $[1,2]$. According to the International Diabetes Federation (IDF), the total diabetes-related health expenditure worldwide is projected have reached USD 760 billion in 2019, with diabetes-related complications being the key cost drivers [1]. China spent an estimated USD 109.0 billion on managing and treating diabetes and its complications in 2019, second only in expenditure to the USA (USD 294.6 billion) [1].

Diabetes-related complications are the key drivers of the economic burden of diabetes. Numerous studies have measured the direct medical costs of diabetes-related complications, although with high between-study variability in data sources, complications of interest, cost measures, among others. To date, published studies in China have always estimated heathcare costs as the average costs per hospitalization for a certain event, or as the cost differences between patients with and without a specific complication [3-6]. A comprehensive set of cost estimates for different complications that take into account medication use and inpatient/outpatient medical services among patients with diabetes based on one single data source is highly recommended [7-10]. Such reliable country-specific cost data on diabetesrelated complications are also essential inputs for the projections of the economic burden of diabetes and for economic evaluation models, such as the Center for Outcomes Research (CORE) Diabetes Model, and the United Kingdom Prospective Diabetes Study (UKPDS) Outcomes Model [11, 12].

Another important issue in published studies relates to the estimation of costs of diabetesrelated complications as these complications are always comorbid within the same patient. It is therefore challenging to estimate the independent economic impact of each complication 
on direct medical costs. In 2018, Katharina Kähm et al. addressed this need by controlling for the confounding effects of comorbid complications within each patient and published the cost estimates of incident complications in patients with T2DM using one health insurance database in Germany [13]. Inspired by this study, the aim of the present study was to provide reliable individual-level cost estimates of managing and treating major diabetes-related complications in patients newly diagnosed patients with T2DM in China.

\section{METHODS}

\section{Data Source}

This was a population-based cohort study which used data on enrollees enrolled in the Urban Employee Basic Medical Insurance (UEBMI) Claims database of Tianjin, China, between 2008 and 2015. Tianjin is a Northern Chinese municipality with 15.6 million inhabitants in 2019 and was ranked seventh among the 31 provinces/municipalities of mainland China in terms of gross domestic product (GDP) per capita in 2019 [14, 15]. Mandatory participation in the UEBMI is planned for all employees and retirees of both public and private companies in all of the provinces/municipalities, including Tianjin; in 2015, about 5.2 million people were enrolled in the UEBMI in Tianjin. The analytical sample in this study was a random sample of all enrollees. The de-identified data extracted included patient-level demographic information, medical claims of inpatient and outpatient service, pharmacy claims, and related medical and medication costs. The Tolerability and Ethics Committee at the School of Pharmaceutical Science and Technology, Tianjin University, waived the requirement of ethics approval for the current study. Informed consent was not required due to the retrospective nature of this study.

\section{Study Population}

Adults individuals (aged $\geq 18$ years) who had been newly diagnosed with T2DM according to the 10th Revision of the International Classification of Diseases (ICD-10) codes E11 and had made one inpatient claim or $\geq 2$ outpatient claims ( $\geq 30$ days apart) between 1 January 2009 and 31 December 2014 were identified. The date of the first T2DM-related diagnosis (index claim) was defined as the index date. Patients were required to have continuous enrollment for at least 12 months preceding the index date (baseline period) and have no diabetes-related claims during the baseline period. Patients who had any diagnosis of type 1 diabetes mellitus (ICD-10 E10) or gestational diabetes mellitus (ICD-10 O24) during the research period were excluded from the analysis. Included patients were followed up from the index date to death, discontinuation, or the end of 2015.

\section{Identification of Complications}

Macrovascular and microvascular complications, including cardiovascular disease, cerebrovascular disease, peripheral vascular disease, foot disease, nephropathy, retinopathy, and neuropathy were examined in this study. The list of complications and the corresponding ICD-10 codes are presented in Electronic Supplementary Material [ESM] Table 1; these complications were identified based on the published literature and confirmed with clinical experts before being applied to the patient [16-19]. Certain cardiovascular and cerebrovascular events, including angina, myocardial infarction (MI), chronic heart failure, arrhythmia, stroke, and transient ischemic attacks (TIA) were analyzed further (ESM Table 1). Following consultation with clinical experts, the acute macrovascular complications (events), including MI and stroke, were only identified in inpatient claims with corresponding primary diagnoses. TIA was identified in inpatient and outpatient claims with the corresponding primary diagnoses. The other complications were identified in both inpatient and outpatient claims with either primary or secondary diagnoses. 


\section{Statistical Analysis}

Baseline characteristics captured during the 12-month baseline period included patient demographics (age, gender), Charlson Comorbidity Index (CCI) score, and comorbidities (hypertension and dyslipidemia). CCI is a weighted index developed to measure comorbid conditions that takes into account both the number and the seriousness of comorbid diseases. Nineteen comorbidities, including MI, congestive heart failure, peripheral vascular disease, among others, were considered, with each condition assigned a weight from 1 to 6 points; these weights were summed to produce the CCI for each patient [20]. The prevalence of examined complications at baseline was also investigated.

The cumulative incidence of examined complications during the follow-up period was calculated by using the number of incident cases for each complication divided by the number of patients who were at risk for that complication during each follow-up year. The incident cases were identified as patients who were newly diagnosed with the specific complication, with related diagnoses absent during the baseline period. Patients who were at risk for the specific complication were patients who were followed up during the given year, excluding patients who had died, were lost to follow-up, or had previously related diagnoses.

Direct medical costs for the examined complications were calculated from the Chinese healthcare system perspective, including the medication and medical costs paid by both the medical insurance and patients. Patients who were newly diagnosed with a certain complication during the follow-up period were included in the corresponding cost analysis. For each incident complication case, the follow-up periods were divided into quarters, with each 90 days (a quarter) considered to be an interval during which the onset of the complication was taken into account. The quarters were consecutively numbered, starting with \#0 and ending with \#28, with \#0 being the prior quarters without a certain complication, \#1 being the quarter during which the complication first occurred (onset of complication), and \#2 to \#28 being the following quarterly intervals. The remaining follow-up time of $<90$ days was not analyzed. Mean costs per quarter for each complication were estimated.

A generalized estimating equations (GEE) model was further constructed to estimate the independent costs of each complication on patients, controlling for the demographics and confounding effects of comorbid complications for each patient. Variables, including age, sex, presence of complications at baseline, and occurrence of different complications, were included in the model. Certain cardiovascular and cerebrovascular diseases, such as MI and stroke, were also included in the model, with 'cardiovascular disease' or 'cerebrovascular disease' excluded due to high correlations. A gamma distribution and a log-link function were used in the GEE model taking into account the non-normal distribution of costs, in accordance with recommendations in the literature $[5,19]$. The coefficients were back-transformed to the ordinal scale using an exponential function to obtain the cost estimates. The costs of each complication were first estimated in the quarterly interval in which the complication occurred (quarter \#1), then in the following quarters within the first year (quarters \#2 to \#4), and finally in subsequent quarters in following years (quarters \#5 to \#28). Specifically, the immediate costs of each complication refer to the additional costs in the quarter during which the complication first occurred (quarter \#1). The costs within the first year of onset for each complication refer to the costs incurred in quarter $\# 1$, plus three times $(3 \times)$ the average quarterly costs of the following quarters within the first year (quarters \#2 to \#4). Annual costs in the follow-up years were further calculated as four times $(4 \times)$ the average quarterly costs among subsequent quarters (quarters \#5 to \#28) [13]. Detailed information on the models can be found in ESM Statistical Appendix. All statistical analyses were conducted using Stata version 13.1 (StataCorp, College Station, TX, USA). 


\section{RESULTS}

\section{Patient Selection and Baseline Characteristics}

A search of the UEBMI Claims database identified 145,885 patients diagnosed with T2DM between 2009 and 2014. After excluding patients who were previously diagnosed with T2DM during the baseline period and patients who had received a diagnosis of type 1 diabetes or gestational diabetes mellitus during the research period, there remained 114,847 patients newly diagnosed with T2DM who were included in the study (Fig. 1). The mean (standrd deviation [SD]) age of this study population was 56.9 (12.4) years, and $45.5 \%$ were female (Table 1). The mean (SD) CCI of the total study cohort was $2.0(1.4)$, with $54.2 \%$ of patients comorbid with hypertension and $34.1 \%$ comorbid with dyslipidemia. Diabetes-related complications and their prevalence among the study cohort at baseline: were nephropathy $(9.0 \%)$, cardiovascular disease $(6.7 \%)$, neuropathy $(6.3 \%)$, cerebrovascular disease (3.8\%), retinopathy $(3.7 \%)$, peripheral vascular disease $(3.4 \%)$, and foot disease $(0.5 \%)$.

\section{Cumulative Incidence for Complications}

Table 2 presents the cumulative incidence of developing complications over the follow-up period. After 7 years the cumulative incidence was highest for nephropathy $(80.8 \%)$, followed by neuropathy $(75.7 \%)$ and peripheral vascular disease $(64.7 \%)$. For certain cardiovascular and cerebrovascular disease complications, after 7 years the cumulative incidence was highest for angina (30.1\%), arrhythmia (22.8\%), stroke $(16.7 \%)$ and chronic heart failure (16.5\%).

\section{Direct Medical Costs}

The descriptive costs for quarters before and after the onset of certain complications are given in Table 3. Costs in the quarter during which the complication first occurred (quarter \#1) were highest for cerebrovascular disease (China yuan [CNY] 18,162), followed by cardiovascular disease (CNY 9340), foot disease (CNY 8044), and peripheral vascular disease (CNY 7721), and relatively lower for nephropathy, neuropathy, and retinopathy, ranging from CNY 6256 to CNY 6715. The costs decreased in quarters \#2 for all complications and then increased slowly in the subsequent quarters. Regarding cardiovascular and cerebrovascular disease, the costs in quarters \#1 were highest for MI (CNY 44,419), stroke (CNY 23,168), and chronic heart failure (CNY $17,804)$. The number of patients included in corresponding quarterly intervals (e.g., 31,203 patients were analyzed in quarter \#0 for cardiovascular disease) are given in ESM Table 2.

The estimated coefficients and predicted cost differences obtained from the GEE model are given in Table 4 . The intercept of CNY 2350 presents the costs for a male patient aged 50-59 years without any complications for a 3-month period. Costs increased steadily with age, and costs for women were slightly less than those for men. Patients with a history of complications appeared to have higher costs relative to those who did not experience any complication, with the additional costs varying between CNY 53 and CNY 2142 per quarter. The immediate costs, i.e., the additional costs in the quarters that the complications occurred, were highest for MI (CNY 19,633), followed by stroke (CNY 9959), and chronic heart failure (CNY 4215), with the costs for other complications ranging from CNY 784 for foot disease to CNY 1766 for TIA. The long-term additional costs were highest for stroke, with an increase of CNY 1716 in the quarters within the first year (i.e., \#2 to \# 4) and of CNY 1087 in quarters of following years (i.e., \#5 to \#28). The expected costs in quarterly intervals and years for subgroups comprised of patients of different age and sex were also calculated and the results are presented in ESM Table 3. As an example we take the costs of stroke among 50- to 59-year-old men. Their stroke-related additional costs in the year of onset are CNY 24,507 (CNY $12,309+3 \times \mathrm{CNY} 4066)$, and the annualized costs in following years are CNY 13,746 (CNY $3437 \times 4)($ ESM Table 3$)$. 


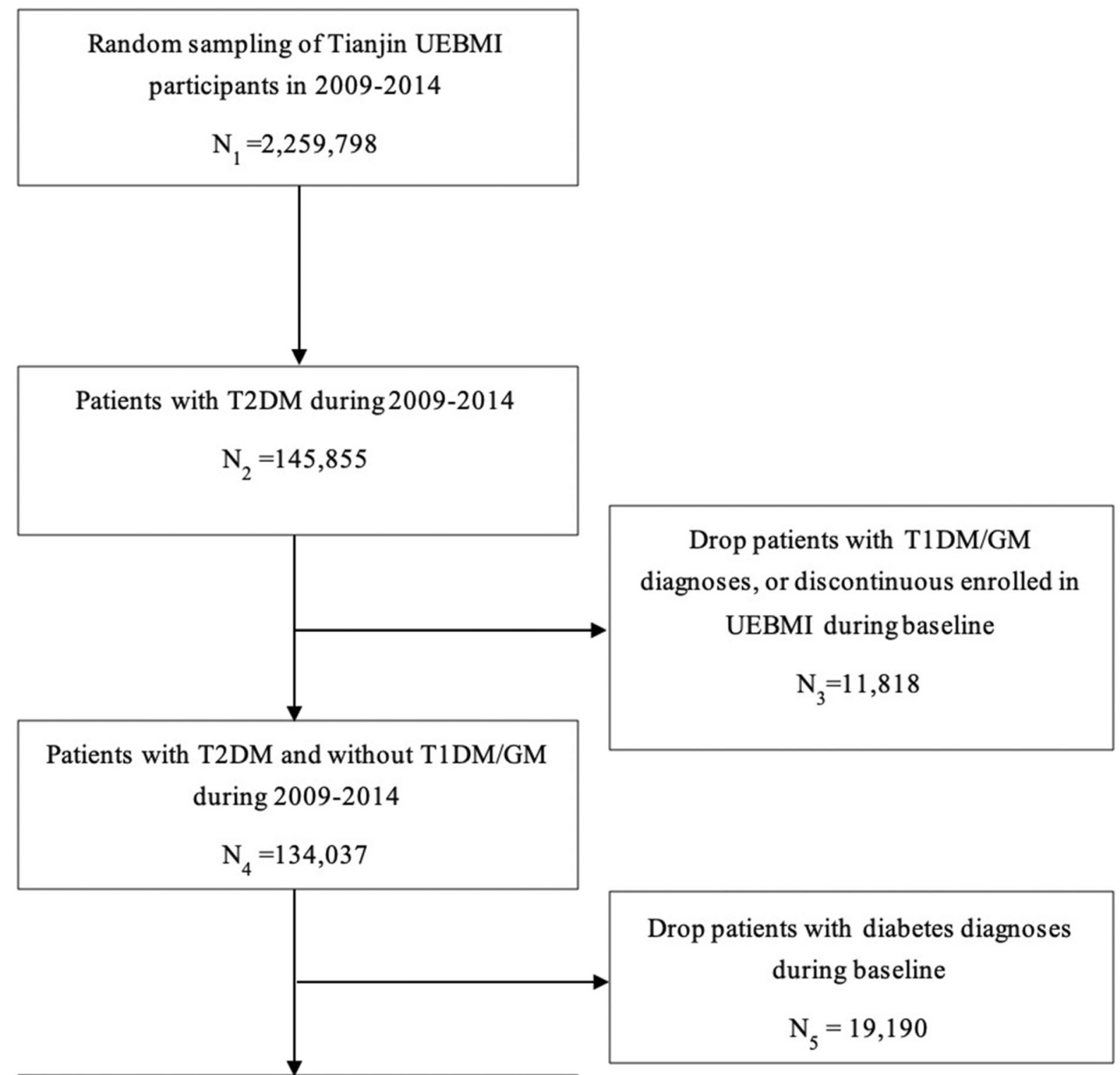

Newly diagnosed patients with T2DM during

$$
\begin{aligned}
& 2009-2014 \\
& \mathrm{~N}_{6}=114,847
\end{aligned}
$$

Fig. 1 Flow chart of patient selection. GM Gestational diabetes, T1DM/T2DM type 1/type 2 diabetes mellitus, UEBMI Urban Employee Basic Medical Insurance

\section{DISCUSSION}

In this study we estimated the cumulative incidence and individual-level costs of chronic complications in patients with T2DM in China. This study differs from previous studies whose aim was to estimate the cost differences between patients with and without one or 
Table 1 Baseline characteristics of the study population

\begin{tabular}{ll}
\hline $\begin{array}{l}\text { Baseline } \\
\text { characteristics }\end{array}$ & $\begin{array}{l}\text { Patients with newly diagnosed } \\
\text { T2DM }(N=114,847)\end{array}$ \\
\hline
\end{tabular}

Demographic characteristics

Age, years $\quad 56.9 \pm 12.4$

Age group, years

$$
\begin{array}{cl}
<40 & 9751(8.5 \%) \\
40,50) & 17,468(15.2 \%) \\
50,60) & 42,668(37.2 \%) \\
60,70) & 27,080(23.6 \%) \\
70,80) & 13,213(11.5 \%) \\
\geq 80 & 4667(4.1 \%) \\
\text { Female } & 52,288(45.5 \%) \\
\text { Charlson } & 2.0 \pm 1.4 \\
\text { Comorbidity } & \\
\text { Index } & \\
\text { Comorbidity } & \\
\text { Hypertension } & 62,270(54.2 \%) \\
\text { Dyslipidemia } & 39,122(34.1 \%)
\end{array}
$$

Chronic complications

$\begin{array}{ll}\begin{array}{l}\text { Cardiovascular } \\ \text { disease }\end{array} & 7750(6.7 \%) \\ \text { Angina } & 3122(2.7 \%) \\ \begin{array}{l}\text { Myocardial } \\ \text { infarction }\end{array} & 524(0.5 \%) \\ \begin{array}{l}\text { Chronic heart } \\ \text { failure }\end{array} & 1602(1.4 \%) \\ \text { Arrhythmia } & 3180(2.8 \%) \\ \begin{array}{l}\text { Cerebrovascular } \\ \text { disease }\end{array} & 4337(3.8 \%) \\ \begin{array}{l}\text { Stroke } \\ \text { Transient }\end{array} & 3486(3.0 \%) \\ \text { ischemic attacks } & 917(0.8 \%) \\ \text { Peripheral } & 3948(3.4 \%) \\ \text { vascular disease } & \\ \text { Foot disease } & 664(0.5 \%)\end{array}$

Table 1 continued

\begin{tabular}{ll}
\hline $\begin{array}{l}\text { Baseline } \\
\text { characteristics }\end{array}$ & $\begin{array}{l}\text { Patients with newly diagnosed } \\
\text { T2DM }(\boldsymbol{N}=\mathbf{1 1 4 , 8 4 7})\end{array}$ \\
\hline Nephropathy & $10,298(9.0 \%)$ \\
Retinopathy & $4208(3.7 \%)$ \\
Neuropathy & $7220(6.3 \%)$ \\
\hline
\end{tabular}

Values in table are presented as the mean \pm standard deviation $(\mathrm{SD})$ or as a number with the percentage in parentheses

T2DM Type 2 diabetes mellitus

${ }^{a}$ Charlson Comorbidity Index (CCI) is a weighted index developed to measure comorbid conditions that takes into account both the number and the seriousness of the comorbid diseases. Nineteen comorbidities were included in the index. Each condition was assigned a weight from 1 to 6 . These weights were summed to produce the CCI score for each patient. Myocardial infarct, congestive heart failure, peripheral vascular disease, cerebrovascular disease, dementia, chronic pulmonary disease, connective tissue disease, ulcer disease, mild liver disease, and diabetes have a score of 1 point. Hemiplegia, moderate or severe renal disease, diabetes with end organ damage, any tumor, leukemia, and lymphoma have a score of 2 points. Moderate or severe liver disease has a score of 3 points. Metastatic solid tumor and acquired immune deficiency syndrome have a score of 6 points

several specific complications, in that it has determined the net incremental costs of all common diabetes-related complications following the occurrence of corresponding complications. This information will be very useful as inputs into economic evaluations and economic burden projections among patients with T2DM in China.

We found that the majority of patients with T2DM were at risk for being newly diagnosed with chronic complications within 7 years, with nephropathy, neuropathy, peripheral vascular disease, and cardiovascular disease being the most common complications. More than 10\% of these patients had diabetes-related complications at baseline, which indicates that people may have had diabetes-related complications prior to receiving a diagnosis of diabetes. In 
Table 2 Cumulative incidence of complications during follow-up period

\begin{tabular}{lccccccc}
\hline Complications & \multicolumn{7}{l}{ Years from index date $^{\mathbf{a}}$} \\
\cline { 2 - 7 } & $\mathbf{1}(\mathbf{\%})$ & $\mathbf{2}(\%)$ & $\mathbf{3}(\mathbf{\%})$ & $\mathbf{4}(\%)$ & $\mathbf{5}(\%)$ & $\mathbf{6}(\%)$ & $\mathbf{7}(\mathbf{\%})$ \\
\hline Cardiovascular disease & 10.2 & 18.3 & 25.6 & 32.6 & 39.6 & 45.9 & 51.9 \\
Angina & 4.4 & 8.4 & 12.5 & 16.8 & 21.4 & 25.9 & 30.1 \\
Myocardial infarction & 0.2 & 0.4 & 0.6 & 0.9 & 1.3 & 1.6 & 2.2 \\
Chronic heart failure & 2.2 & 4.1 & 6.1 & 8.2 & 10.4 & 13.2 & 16.5 \\
Arrhythmia & 3.9 & 7.2 & 10.2 & 13.4 & 16.5 & 19.7 & 22.8 \\
Cerebrovascular disease & 3.4 & 6.3 & 9.1 & 12.0 & 15.0 & 18.3 & 21.7 \\
Stroke & 2.5 & 4.7 & 7.0 & 9.4 & 11.8 & 14.3 & 16.7 \\
Transient ischemic attacks & 1.1 & 2.1 & 3.1 & 4.0 & 5.2 & 6.5 & 8.0 \\
Peripheral vascular disease & 18.4 & 26.3 & 38.6 & 46.2 & 52.9 & 59.0 & 64.7 \\
Foot disease & 5.1 & 8.4 & 11.6 & 14.4 & 17.0 & 19.4 & 21.6 \\
Nephropathy & 32.3 & 47.8 & 58.5 & 66.4 & 72.5 & 76.9 & 80.8 \\
Retinopathy & 16.4 & 26.8 & 36.3 & 44.5 & 51.6 & 57.5 & 62.1 \\
Neuropathy & 27.6 & 40.9 & 51.2 & 59.3 & 66.2 & 71.7 & 75.7 \\
\hline
\end{tabular}

Cumulative incidence is defined as the number of incident cases for each complication divided by the number of patients who were at risk for that complication during each follow-up year, and is presented as a percentage for that year

${ }^{a}$ Index date was defined as the date of the first T2DM-related diagnosis (index claim)

general, our estimates are higher than those in epidemiology data published in developed countries, including the UK [21], the USA [22], and Germany [23], even given the similar or even younger mean ages in these study populations. Definitions and/or diagnoses criteria of complications were not standardized in these earlier study, which is why we clarified the identification process in detail, including the ICD codes and primary or secondary diagnoses criteria we used. Ethnic variations may also exist in the development of diabetes-related complications. It has been suggested that Asian populations are at higher risk of developing kidney disease and macrovascular disease, such as stroke [24, 25].

Most of the published epidemiological studies in China have focused on existing patients instead of incident patients and have estimated the prevalence of chronic diabetes-related complications instead of the cumulative incidence, primarily due to limitations in terms of data sources [26-28]. It is therefore challenging to directly compare our incidence estimates with those of these previous studies in China. For example, the prevalence of stroke was $15.6 \%$ among patients with prevalent diabetes according to Duan et al., while the corresponding cumulative incidence for stroke in our study was $2.5 \%$ for the first year following confirmed diabetes diagnoses, $7 \%$ after 3 years, and $16.7 \%$ after 7 years [26].

Compared with baseline quarters, the occurrence of diabetes-related complications increased the healthcare costs substantially in the quarter during which the complication occurred, and also continued to increase costs in subsequent quarters. Similar results were also observed in the USA [29] and German [13] studies. Acute and severe complications, including MI and stroke, were associated with a high peak in the incident quarter, while chronic 
Table 3 Distribution of direct medical costs before and after onset of chronic complications in quarterly intervals (in China yuan)

\begin{tabular}{|c|c|c|c|c|c|c|c|c|c|}
\hline \multirow[t]{2}{*}{ Complications } & \multicolumn{9}{|c|}{ Quarterly intervals ${ }^{\mathbf{a}}$} \\
\hline & $\# \mathbf{0}$ & $\# 1$ & $\# 4$ & $\# 8$ & $\# 12$ & $\# 16$ & $\# 20$ & $\# 24$ & $\# 28$ \\
\hline Cardiovascular disease & 4643 & 9340 & 5103 & 5774 & 6173 & 6408 & 7295 & 7526 & 7714 \\
\hline Angina & 4657 & 7964 & 5010 & 5877 & 6309 & 6189 & 6795 & 6874 & 8868 \\
\hline Myocardial infarction & 4648 & 44,419 & 6151 & 5853 & 5031 & 6121 & 11,196 & 10,065 & 3090 \\
\hline Chronic heart failure & 6199 & 17,804 & 7596 & 7444 & 7511 & 7659 & 9214 & 9278 & 7007 \\
\hline Arrhythmia & 4578 & 6099 & 4774 & 5480 & 6006 & 6305 & 6652 & 6978 & 6458 \\
\hline Cerebrovascular disease & 4377 & 18,162 & 6392 & 7051 & 7486 & 7884 & 8145 & 8726 & 6146 \\
\hline Stroke & 4678 & 23,168 & 7446 & 7834 & 8279 & 8558 & 8406 & 9487 & 5911 \\
\hline Transient ischemic attacks & 4139 & 7719 & 4516 & 5180 & 5769 & 6341 & 7557 & 6562 & 7790 \\
\hline Peripheral vascular disease & 3899 & 7721 & 6061 & 6513 & 6800 & 7484 & 7905 & 8420 & 7837 \\
\hline Foot disease & 5176 & 8044 & 6962 & 7126 & 7399 & 7804 & 8198 & 8682 & 9864 \\
\hline Nephropathy & 3188 & 6256 & 5043 & 5643 & 6210 & 6856 & 7486 & 8521 & 7818 \\
\hline Retinopathy & 4118 & 6637 & 6061 & 6483 & 6826 & 7552 & 7782 & 8609 & 8288 \\
\hline Neuropathy & 3418 & 6715 & 5352 & 5857 & 6278 & 6889 & 7426 & 8093 & 8691 \\
\hline
\end{tabular}

${ }^{a}$ The follow-up periods were divided into quarters, with each 90 days (a quarter) considered to be an interval during which the onset of the complication was taken into account. The quarters were consecutively numbered, starting with \#0 and ending with \#28, with \#0 being the prior quarters without a certain complication, \#1 being the quarter during which the complication first occurred (onset of complication), and $\# 2$ to \#28 being the following quarterly intervals

disease, such as retinopathy, nephropathy, or foot complication, was associated with relatively slight peak. We also found that women had lower healthcare costs than men and that the total costs peaked among patients aged between 70 and 80 years. However, we did not consider the interactions between age, sex, and presence of complications, the existence of which has been implied by a previous study conducted in Germany [13].

Direct comparisons of the cost estimates reported in this study and those reported in previous studies in other countries may have limited value due to the various treatment patterns and healthcare systems across different countries. The published studies based on the Chinese population with diabetes have paid more attention to the costs per complicationrelated hospitalization or to the cost differences between prevalent diabetes patients with a different number of complications (e.g., 0, 1, $2+)$, and did not provide the sex- and agespecific net additional costs of each common chronic diabetes complication. For example, a cross-sectional study published in 2018 reported that the total annual costs were highest for diabetic foot (USD 5207, around CNY 35,512), while the costs for stroke were USD 1724 (around CYN 11,758) [30]. In comparison, in our study the additional costs for foot disease among male patients aged 60 to 70 years were CNY 12,288 for the first year and CNY 11,390 for the second and following years (ESM Table 3), and those for stroke were CNY 25,976 in the first year year and CNY 14,570 for the second and following years .

Our findings should be interpreted with caution. First, given the unavailability of national longitudinal claims database in China, we used the Tianjin UEBMI claims database to 
Table 4 Effects of chronic type 2 diabetes mellitus complications on direct medical costs per quarter in the generalized estimating equations model with gamma distribution and a log-link function

\begin{tabular}{|c|c|c|c|}
\hline Variable & Coefficient (SE) & $\operatorname{Exp}$ (coefficient) & $\Delta \operatorname{Cost}(\mathrm{CNY})$ \\
\hline Constant & $7.76^{* * *}(0.01)$ & 2350 & - \\
\hline Sex: female (Reference $=$ male $)$ & $-0.04^{* * *}(0.01)$ & 0.96 & -83 \\
\hline \multicolumn{4}{|l|}{ Age group (Reference $=50-59$ years) } \\
\hline$<40$ & $-0.07^{* * *}(0.01)$ & 0.93 & -164 \\
\hline $40-50$ & $-0.10^{* * *}(0.01)$ & 0.9 & -233 \\
\hline $60-70$ & $0.06^{* * *}(0.01)$ & 1.06 & 141 \\
\hline $70-80$ & $0.07^{* * *}(0.01)$ & 1.07 & 160 \\
\hline$\geq 80$ & $0.06^{* * *}(0.01)$ & 1.06 & 136 \\
\hline \multicolumn{4}{|c|}{ Baseline complications $($ Reference $=$ no $)$} \\
\hline Angina & $0.03(0.03)$ & 1.03 & 78 \\
\hline Myocardial infarction & $0.40^{* * *}(0.05)$ & 1.49 & 1155 \\
\hline Chronic heart failure & $0.43^{* * *}(0.04)$ & 1.53 & 1248 \\
\hline Arrhythmia & $0.00^{* * *}(0.03)$ & 1.00 & 0 \\
\hline Stroke & $0.65^{* * *}(0.02)$ & 1.91 & 2142 \\
\hline Transient ischemic attacks & $0.02(0.05)$ & 1.02 & 53 \\
\hline Peripheral vascular disease & $0.27^{* * *}(0.02)$ & 1.31 & 737 \\
\hline Foot disease & $0.17^{* * *}(0.04)$ & 1.18 & 432 \\
\hline Nephropathy & $0.39^{* * *}(0.02)$ & 1.48 & 1126 \\
\hline Retinopathy & $0.12^{* * *}(0.02)$ & 1.13 & 310 \\
\hline Neuropathy & $0.15^{* * *}(0.02)$ & 1.16 & 368 \\
\hline Death & $0.57^{* * *}(0.04)$ & 1.77 & 1820 \\
\hline \multicolumn{4}{|c|}{ Onset of complications (Reference $=$ no $)$} \\
\hline \multicolumn{4}{|l|}{ Angina } \\
\hline Quarter of onset of complication & $0.56^{* * *}(0.02)$ & 1.74 & 1746 \\
\hline Quarters \#2 to \#4 & $0.03^{* *}(0.01)$ & 1.03 & 68 \\
\hline Quarters \#5 to \#28 & $0.03^{* *}(0.01)$ & 1.04 & 83 \\
\hline \multicolumn{4}{|l|}{ Myocardial infarction } \\
\hline Quarter of onset of complication & $2.24^{* * *}(0.04)$ & 9.36 & 19,633 \\
\hline Quarters \#2 to \#4 & $0.41^{* * *}(0.05)$ & 1.51 & 1202 \\
\hline Quarters \#5 to \#28 & $0.05(0.04)$ & 1.06 & 133 \\
\hline \multicolumn{4}{|l|}{ Chronic heart failure } \\
\hline Quarter of onset of complication & $1.03^{* * *}(0.02)$ & 2.79 & 4215 \\
\hline
\end{tabular}


Table 4 continued

\begin{tabular}{|c|c|c|c|}
\hline Variable & Coefficient (SE) & Exp (coefficient) & $\Delta$ Cost $(\mathrm{CNY})$ \\
\hline Quarters \#2 to \#4 & $0.29^{* * *}(0.02)$ & 1.34 & 788 \\
\hline Quarters \#5 to \#28 & $0.21^{* * *}(0.02)$ & 1.24 & 557 \\
\hline \multicolumn{4}{|l|}{ Arrhythmia } \\
\hline Quarter of onset of complication & $0.32^{* * *}(0.02)$ & 1.37 & 873 \\
\hline Quarters \#2 to \#4 & $0.00(0.01)$ & 1.00 & 9 \\
\hline Quarters \#5 to \#28 & $0.02(0.01)$ & 1.02 & 52 \\
\hline \multicolumn{4}{|l|}{ Stroke } \\
\hline Quarter of onset of complication & $1.66^{* * *}(0.02)$ & 5.24 & 9959 \\
\hline Quarters \#2 to \#4 & $0.55^{* * *}(0.02)$ & 1.73 & 1716 \\
\hline Quarters \#5 to \#28 & $0.38^{* * *}(0.01)$ & 1.46 & 1087 \\
\hline \multicolumn{4}{|l|}{ Transient ischemic attacks } \\
\hline Quarter of onset of complication & $0.56^{* * *}(0.02)$ & 1.75 & 1766 \\
\hline Quarters \#2 to \#4 & $-0.02(0.02)$ & 0.98 & -54 \\
\hline Quarters \#5 to \#28 & $-0.01(0.02)$ & 0.99 & -32 \\
\hline \multicolumn{4}{|l|}{ Peripheral vascular disease } \\
\hline Quarter of onset of complication & $0.50^{* * *}(0.01)$ & 1.65 & 1523 \\
\hline Quarters \#2 to \#4 & $0.30^{* * *}(0.01)$ & 1.35 & 823 \\
\hline Quarters \#5 to \#28 & $0.31^{* * *}(0.01)$ & 1.36 & 855 \\
\hline \multicolumn{4}{|l|}{ Foot disease } \\
\hline Quarter of onset of complication & $0.29^{* * *}(0.01)$ & 1.33 & 784 \\
\hline Quarters \#2 to \#4 & $0.18^{* * *}(0.01)$ & 1.20 & 470 \\
\hline Quarters \#5 to \#28 & $0.13^{* * *}(0.01)$ & 1.14 & 337 \\
\hline \multicolumn{4}{|l|}{ Nephropathy } \\
\hline Quarter of onset of complication & $0.46^{* * *}(0.01)$ & 1.58 & 1370 \\
\hline Quarters \#2 to \#4 & $0.27^{* * *}(0.01)$ & 1.31 & 737 \\
\hline Quarters \#5 to \#28 & $0.28^{* * *}(0.01)$ & 1.33 & 767 \\
\hline \multicolumn{4}{|l|}{ Retinopathy } \\
\hline Quarter of onset of complication & $0.31^{* * *}(0.01)$ & 1.36 & 838 \\
\hline Quarters \#2 to \#4 & $0.21^{* * *}(0.01)$ & 1.24 & 559 \\
\hline Quarters \#5 to \#28 & $0.22^{* * *}(0.01)$ & 1.25 & 592 \\
\hline \multicolumn{4}{|l|}{ Neuropathy } \\
\hline Quarter of onset of complication & $0.42^{* * *}(0.01)$ & 1.52 & 1212 \\
\hline
\end{tabular}


Table 4 continued

\begin{tabular}{lcll}
\hline Variable & Coefficient (SE) & Exp (coefficient) & $\Delta$ Cost (CNY) \\
\hline Quarters \#2 to \#4 & $0.12^{* * *}(0.01)$ & 1.13 & 295 \\
Quarters \#5 to \#28 & $0.11^{* * *}(0.01)$ & 1.12 & 272 \\
\hline
\end{tabular}

$C N Y$ China yuan, $S E$ standard error

${ }^{* *},{ }^{* * *}$ Significant at ${ }^{* *} P<0.01$ and ${ }^{* * *} P<0.001$

estimate the China-specific cumulative incidence and individual-level costs of chronic complications in patients with T2DM. Our estimates may be relatively higher than the average costs in China since Tianjin is a more economically developed region (GDP per capita in 2019: CNY 90,371) compared with the national average level (GDP per capita in 2019: CNY 70,892) $[14,15]$. The UEBMI is also relatively superior to other social medical insurance plans in China, such as the Urban Resident Basic Medical Insurance, in terms of its lower deductible and higher reimbursement rate. Second, some diseases, such as cardiovascular and cerebrovascular disease, may occur prior to the diagnosis of diabetes, which means part of the costs might not have been caused by diabetes. Thirdly, we also acknowledge the limitations resulting from the use of medical claims data, including potential misclassifications of diagnoses and lack of clinical variables, such as blood glucose, lipid and blood pressure control. The impact of clinical markers on the occurrences of complications should be investigated in future studies. Lastly, severe complications, such as endo-organ renal disease, retinopathy resulting in blindness, and amputation of limbs, were included in the corresponding disease category and were not analyzed separately. The sample sizes of these severe complications were very small in our database due to relatively limited follow-up period or diabetes duration.

\section{CONCLUSIONS}

In conclusion, the present study shows that healthcare costs increase substantially in the quarter during which the diabetes-related complication occurs and that these continue to increase, with smaller differences between subsequent years. Our findings will provide support for future economic research and economic modelling conducted among patients with T2DM in China, which will further guide evidence-based clinical and policy decisionmaking.

\section{ACKNOWLEDGEMENTS}

Funding. No funding or sponsorship was received for this study or publication of this article. The Rapid Service Fee was funded by Tianjin University.

Authorship. All named authors meet the International Committee of Medical Journal Editors (ICMJE) criteria for authorship for this article, take responsibility for the integrity of the work as a whole, and have given their approval for this version to be published.

Disclosures. Xiaoning He, Yawen Zhang, Yan Zhou, Chaohui Dong and Jing $\mathrm{Wu}$ have nothing to disclose.

Compliance with Ethics Guidelines. The Tolerability and Ethics Committee at the School of Pharmaceutical Science and Technology, Tianjin University, waived the requirement of ethics approval for the current study. Informed consent was not required due to the retrospective nature of this study.

Data Availability. The datasets generated during and/or analyzed during the current 
study are not publicly available as this was a retrospectively observational study using the de-identified medical claims data.

Open Access. This article is licensed under a Creative Commons Attribution-NonCommercial 4.0 International License, which permits any non-commercial use, sharing, adaptation, distribution and reproduction in any medium or format, as long as you give appropriate credit to the original author(s) and the source, provide a link to the Creative Commons licence, and indicate if changes were made. The images or other third party material in this article are included in the article's Creative Commons licence, unless indicated otherwise in a credit line to the material. If material is not included in the article's Creative Commons licence and your intended use is not permitted by statutory regulation or exceeds the permitted use, you will need to obtain permission directly from the copyright holder. To view a copy of this licence, visit http://creativecommons.org/licenses/bync/4.0/.

\section{REFERENCES}

1. International Diabetes Federation. IDF diabetes atlas, ninth edition. 2019. https://diabetesatlas.org/ en/resources/. Accessed 30 Oct 2020.

2. Menke A, Casagrande S, Geiss L, Cowie CC. Prevalence of and trends in diabetes among adults in the United States, 1988-2012. JAMA. 2015;314:2021-9.

3. Chen D, Liu S, Tan X, Zhao Q. Assessment of hospital length of stay and direct costs of type 2 diabetes in Hubei, Province, China. BMC Health Serv Res. 2017;17:199.

4. Alva ML, Gray A, Mihaylova B, Leal J, Holman RR. The impact of diabetes-related complications on healthcare costs: new results from the UKPDS (UKPDS 84). Diabet Med. 2015;32:459-66.

5. Li H, Chen BK, Shah N, et al. Socioeconomic correlates of inpatient spending for patients with type 2 diabetes mellitus in China: evidence from Hangzhou. Exp Clin Endocrinol Diabetes. 2012;120: $35-44$.

6. Wang W, Fu C, Pan C, et al. How do type 2 diabetes mellitus-related chronic complications impact direct medical cost in four major cities of urban China? Value Health. 2009;12:923-9.

7. O'Brien JA, Shomphe LA, Kavanagh PL, et al. Direct medical costs of complications resulting from type 2 diabetes in the US. Diabetes Care. 1998;21: 1122-8.

8. O'Brien JA, Patrick AR, Caro J. Estimates of direct medical costs for microvascular and macrovascular complications resulting from type 2 diabetes mellitus in the United States in 2000. Clin Ther. 2003;25:1017-38.

9. Ward A, Alvarez P, Vo L, Martin S. Direct medical costs of complications of diabetes in the United States: estimates for event-year and annual state costs (USD 2012). J Med Econ. 2014;17:176-83.

10. Yeaw J, Halinan S, Hines D, et al. Direct medical costs for complications among children and adults with diabetes in the US commercial payer setting. Appl Health Econ Health Policy. 2014;12:219-30.

11. Palmer AJ, Roze S, Valentine WJ, et al. The CORE Diabetes Model: projecting long-term clinical outcomes, costs and cost-effectiveness of interventions in diabetes mellitus (types 1 and 2) to support clinical and reimbursement decision-making. Curr Med Res Opin. 2004;20(Suppl 1):S5-26.

12. Clarke PM, Gray AM, Briggs A, et al. A model to estimate the lifetime health outcomes of patients with type 2 diabetes: the United Kingdom Prospective Diabetes Study (UKPDS) outcomes model (UKPDS no. 68). Diabetologia. 2004;47: 1747-59.

13. Katharina $\mathrm{K}$, Michael L, Udo S, et al. Health care costs associated with incident complications in patients with type 2 diabetes in Germany. Diabetes Care. 2018;41(5):971-8.

14. National Bureau of Statistics of China. Statistical bulletin of national economic and social development 2019. https://jzd.stats.gov.cn/xxgk/system/ 2020/07/27/010004034.shtml. Accessed 30 Oct 2020.

15. National Bureau of Statistics of China. https://data. stats.gov.cn/mapdata.htm?cn=E0103. Accessed 30 Oct 2020 .

16. Koo BK, Lee $\mathrm{CH}$, Yang BR, et al. The incidence and prevalence of diabetes mellitus and related atherosclerotic complications in Korea: a National Health Insurance Database Study. PLoS ONE. 2014;9:e110650.

17. Domeikienè A, Vaivadaitė J, Ivanauskienè R, et al. Direct cost of patients with type 2 diabetes mellitus 
healthcare and its complications in Lithuania. Medicina. 2014;50:54-60.

18. Glasheen WP, Renda A, Dong Y. Diabetes Complications Severity Index (DCSI) - update and ICD-10 translation. J Diabetes Complicat. 2017;31: 1007-13.

19. Ringborg A, Yin DD, Martinell M, et al. The impact of acute myocardial infarction and stroke on health care costs in patients with type 2 diabetes in Sweden. Eur J Cardiovasc Prev Rehabil. 2009;16:576-82.

20. Charlson ME, Pompel P, Ales KL, Ronald MC. A new method of classifying prognostic comorbidity in longitudinal studies: development and validation. J Chronic Dis. 1987;40:373-83.

21. Pantalone KM, Misra-Hebert AD, Hobbs TM, et al. Impact of glycemic control on the diabetes complications severity index score and development of complications in people with newly-diagnosed type 2 diabetes. J Diabetes. 2017;10:192-9.

22. Fitch K, Engel T, Sander S, et al. Cardiovascular event incidence and cost in type 2 diabetes mellitus: a Medicare claims-based actuarial analysis. Curr Med Res Opin. 2017;33:1795-801.

23. Boehme MW, Buechele G, Frankenhauser-Mannuss J, et al. Prevalence, incidence and concomitant comorbidities of type 2 diabetes mellitus in South Western Germany-a retrospective cohort and case control study in claims data of a large statutory health insurance. BMC Public Health. 2015;15:855.

24. Clarke PM, Glasziou P, Patel A, et al. Event rates, hospital utilization, and costs associated with major complications of diabetes: a multicountry comparative analysis. PLoS Med. 2010;7:e1000236.

25. U.S. Renal Data System. Annual data report: atlas of end-stage renal disease in the United States. Bethesda: National Institutes of Health/National Institute of Diabetes and Digestive and Kidney Diseases; 2003.

26. Duan X, Li Y, Liu Q, et al. Epidemiological characteristics, medical costs and healthcare resource utilization of diabetes-related complications among Chinese patients with type 2 diabetes mellitus. Expert Rev Pharmacoecon Outcomes Res. 2018;21: S40.

27. Huang Y, Vemer P, Zhu J, et al. Economic burden in Chinese patients with diabetes mellitus using electronic insurance claims data. PLoS ONE. 2016;11: e0159297.

28. Xiang H. Study on prevalence rates of hypertension and chronic diabetic complications of in-patients with diabetes. Chin J Epidemiol. 2003;24:819-21.

29. Pelletier EM, Smith PJ, Boye KS, Misurski DA, Tunis $\mathrm{SL}$, Minshall ME. Direct medical costs for type 2 diabetes mellitus complications in the US commercial payer setting: a resource for economic research. Appl Health Econ Health Policy. 2008;6: 103-12.

30. Wu H, Eggleston $\mathrm{KN}$, Zhong J, et al. How do type 2 diabetes mellitus (T2DM)-related complications and socioeconomic factors impact direct medical costs? A cross-sectional study in rural Southeast China. BMJ Open. 2018;8:e020647. 